\title{
Best Probability Distribution for Rainfall Analysis suited for University of Uyo, Ikpa watershed of Akwa Ibom State, Nigeria
}

\author{
Israel Ifechukwude Ahuchaogu ${ }^{\mathrm{a}^{*}}$, Temitayo Abayomi Ewemoje ${ }^{\mathrm{b}}$, and Ime Etim ${ }^{\mathrm{a}}$ \\ $\mathrm{a}^{*}$ Department of Agricultural and Food Engineering, University of Uyo, Nigeria. \\ ${ }^{\mathrm{b}}$ Department of Agricultural and Environmental Engineering, University of Ibadan, Nigeria.
}

\begin{abstract}
The study is based on determining the probability distribution best suited for the studied area watershed. Previous works have suggested some probability distributions covering the region within which the study area lies without specifying the appropriate distributions suited to the area. This gap in knowledge is what this research is focused on. Rainfall data spanning 33 years $(1981$ - 2013) for the study was obtained from the Nigerian Meteorological Agency (NIMET). Average rainfall magnitude for each year was determined and sorted in descending order of magnitude for the purpose of determining the exceedance probatility and hence the return period using three different plotting positions: Weibull, California and Hazen respectively. The annual maximum value, annual minimum value, standard deviation, variance and coefficient of variation were determined. Year 1983 and 2012 recorded the least and highest total annual rainfall magnitude. The values of the statistic parameters obtained for years 1983 and 2012 were: Mean - 128.49, 385.56; standard deviation - 101.84, 289.45; variance - 10371.62, 83781.11; and coefficient of variation $0.324645,0.317414$. The three distributions were used to predict rainfall magnitude for return periods of $1.25,2,5,10$, 20, 50 and 100 years respectively. Log Normal (LN) distribution recorded the highest predicted rainfall value of $186.266 \mathrm{~mm}$ while Pearson Type III (PT3) recorded the lowest value of $150.347 \mathrm{~mm}$ for the return period of $1.25 y$ ear and PT3 had the highest predicted rainfall magnitude of $\mathbf{5 6 1 . 0 3 8}$ mm for 100years return period while $L N$ and Extreme Value Type I (EVT I) recorded $337.924 \mathrm{~mm}$ and $401.144 \mathrm{~mm}$ respectively. Hazen plotting position was observed to best fitted the three adopted probability distributions employed in the analysis. The order of fitting perfectly to the three probability distributions of Log Normal, Pearson Type III and Extreme Value Type I also called Gumbel when matched with the three plotting positions are in the increasing order: Hazen > Weibull > California. Therefore, Log Normal, Pearson Type III and Extreme Value Type I distributions are suitable for the studied area and recommended for its rainfall anaylsis.
\end{abstract}

Keywords: Rainfall data, hydrological analysis, Probability distributions, Ikpa Watershed, Nigeria.

\section{INTRODUCTION}

The design of hydraulic structures and most water resources engineering related works requires the use of rainfall data for various reasons. In the design of hydraulic structures like dams, culverts, etc, it is needful for, among other things, to determine the discharge capacities and other parameters needed for their construction, effective and efficient functionality. While for irrigation, drainage, flood control, flood forecasting, drought prediction etc, rainfall data is an indispensable raw material among other vital data for the design and effective workability of such water resource engineering processes, Arora (2012), Akan (2006), Khatsuria (2005) and Raghunath (2006).

Rainfall within the concerned watershed where the intended water resources and irrigation facilities are intended to be cited are usually subjected to probability distribution functions commonly used to fit there suitability. There are many probability distributions used in the analysis of rainfall data. These include but not limited to Normal, Log Normal, Exponential, Pearson Type III, Log Pearson Type III, Gumbel, Log Gumbel, Gamma, etc Chow, et al (1988). Olafintoye, et al (2009) studied twenty stations in Nigeria having fifty-four years rainfall data performing frequency analysis using different probability distributions and later subjected them to goodness of fit tests (komogorov sminorv test) in order to determine which is appropriate for each station. Concluding their finding for Calabar and Port-Harcourt, Log-Pearson type III and Pearson type III were recommended for use in basins that falls within these cities which is mostly the south-south of Nigeria.

Dike and Nwachukwu (2003) conclusively suggested that the Log-Normal distribution should be used for predictions of annual rainfall in Port-Harcourt and the rainfall pattern in this zone (South-South) is best described by the Pearson type III and Log-Pearson type III distributions respectively. Validating their research findings, Okonkwo and Mbajiorgu (2010) recommended the use of Log-Normal, Type I Extreme value (Gumbel), Type III Extreme Value and Pearson Type III distributions for describing extreme value data (annual Maxima) for the region as the best.

In other part of Nigeria, Ewemoje and Ewemooje (2011) discussed how Normal, Log-Normal and Log-Pearson type III distributions were investigated as distribution for modeling at-site annual maximum flood flows using different plotting positions of Hazen, Weibull and California for Ogun-Oshun river basin in South West Nigeria. They concluded that Log- Pearson type III distribution has the least absolute difference for all the plotting positions and hence adjudged the best for the river basin studied. They also suggested that Log - Pearson type 
III distribution with Weibull plotting position is best for the basin while predicting a maximum flood with a return period of 25years and 50years respectively.

Therefore, Log-Normal, Extreme value type I (Gumbel), Extreme value type III, Log-Pearson type III and Pearson type III are unarguably the most suggested probability distribution models that could be used in analysis of runoff, rainfall and flood events within the study area of concern in this research. However, for this study, Log-Normal, Extreme value type I (Gumbel) and Pearson type III distributions would be used with Hazen, Weibull and California plotting positions. The essence is to determine which of these suggested distributions best suit the study area. The various probability density functions (PDF) describing these distributions used for this research is expressed, according to Chow, et al (1988) as:

Log-Normal Distribution

$$
f(x)=\frac{1}{x \sigma \sqrt{2 \pi}} \exp \left(-\frac{\left(y-\mu_{y}\right)^{2}}{2 \sigma_{y}^{2}}\right)
$$

Where $y=\log x$, the equations for parameters in terms of the sample moments are

$$
\mu_{y}=\bar{y} \text { and } \sigma_{y}=s_{y} \text { within the range } x>0
$$

Pearson Type III Distribution (Three parameter gamma)

$$
f(x)=\frac{\lambda^{\beta}(x-\varepsilon)^{\beta-1} \ell^{-\lambda(x-\varepsilon)}}{\Gamma(\beta)}
$$

The equations for parameters in terms of the sample moments are

$\lambda=\frac{s_{y}}{\sqrt{\beta}}, \quad \beta=\left(\frac{2}{C_{s}}\right)^{2}$ and $\varepsilon=\bar{x}-s_{x} \sqrt{\beta}$ within the range $x \geq \varepsilon$

Extreme Value Type I (Gumbel)

$$
f(x)=\frac{1}{\alpha} \exp \left[-\frac{x-\mu}{\alpha}-\exp \left(-\frac{x-\mu}{\alpha}\right)\right]
$$

The equations for parameters in terms of the sample moments are

$\alpha=\frac{\sqrt{6 s_{y}}}{\pi}$ and $\mu=\bar{x}-0.5772 \alpha$ within the range $-\infty<x<\infty$

The frequency factors $\left(\mathrm{K}_{\mathrm{T}}\right)$ for Log-Normal, Extreme Value Type I (Gumbel) and Pearson Type III could be computed, according to Ke -Sheng, et al (2006), Subramanya (2002), Mays (2001), Kite (1977), Ewemoje and Ewemooje (2011), Izinyon and Ajumuka (2013), Mustafa and Yusuf (1999), Chow (1951) and other notable researchers and scholars are as shown below:

For Log-Normal, the frequency factor, $\mathrm{Z}$ or $\mathrm{K}_{\mathrm{T}}$ is expressed as shown in equations 4 and 5 respectively.

$Z=W-\frac{\left(2.515517+0.80285 W+0.010328 W^{2}\right)}{1+1.432788 W+0.189269 W^{2}+0.001308 W^{3}}$

Where $W=\sqrt{L N\left(\frac{1}{P^{2}}\right)}, 0 \prec P \leq 0.5$

$\mathrm{P}$ is the probability of exceedance, where $\mathrm{P}>0.5,1-\mathrm{P}$ is substituted for $\mathrm{P}$. the value of $\mathrm{Z}$ is returned with a negative sign when this method is adopted.

$$
K_{T}=\frac{\exp \left[\left\{L N\left(1+C_{V}^{2}\right)\right\}^{1 / 2} Z-\left[L N\left(1+C_{V}^{2}\right)\right]\right] / 2-1}{C_{V}}
$$

Where $C_{V}=\frac{\sigma}{\mu}$, the coefficient of variation of $\mathrm{X}$ and $\mathrm{Z}$ is the standard normal deviate with exceedance probability of $\frac{1}{T}$. However, equation 4 was used in determining the value of $\mathrm{Z}$ for this study. For Extreme value Type I (EVI) and Pearson Type III (PT3) distributions, the researchers cited earlier opined that their frequency factors, $\mathrm{K}_{\mathrm{T}}$, could be evaluated from equations 6 and 7 as expressed below, Al- Suhili and Khanbilvardi (2014), Md. Mohsan and Farhana (2013):

$$
K_{T}=-\frac{\sqrt{6}}{\pi}\left\langle 0.5772+L N\left[L N\left(\frac{T}{T-1}\right)\right]\right\rangle
$$

And

$$
K_{T} \approx Z+\left(Z^{2}-1\right) K+\frac{1}{3}\left(Z^{3}-6 Z\right) K^{2}-\left(Z^{2}-1\right) K^{3}+Z K^{4}+\frac{1}{3} K^{5}
$$

Where $K=\frac{G_{x}}{6}$ and $\mathrm{G}_{\mathrm{x}}$ is the Skewness Coefficient and $\mathrm{Z}$ is the standard normal deviate with exceedance probability of $\frac{1}{T}$, see Table 1 . The statistical variate and predicted discharges using either the LN, EVT I or PT 3 probability distributions were obtained generally from the equation of the form shown in equation 8 where $X_{T}$ is the observed discharge for the year under consideration or the predicted discharges (variate of the annual maximum

discharge) for the adopted return periods, $\bar{X}$ is the mean annual maximum discharge, $\mathrm{Z}$ or $\mathrm{K}_{\mathrm{T}}$ is the frequency factor for either of the probability distributions as expressed in equations $4-7$ and $\sigma_{X}$ is their corresponding standard deviations.

$$
X_{T}=\bar{X}+K_{T}(Z) \sigma_{X}
$$

Table 1. Some Plotting Position and their Probability of

\begin{tabular}{lll}
\hline S/N & Plotting Position & $\begin{array}{c}\text { Exceedance } \\
\text { Probability of } \\
\text { Exceedance (P) }\end{array}$ \\
\hline 1 & Weibull & $\frac{m}{(n+1)}$ \\
2 & California & $\frac{m}{n}$ \\
3 & Hazen & $\frac{(2 m-1)}{2 n}$ \\
4 & Tukey & $\frac{(3 m-1)}{(3 n+1)}$ \\
5 & Gringorten & $\frac{m-a}{n+1-2 a}$ \\
\hline
\end{tabular}

Source: Haan (1994) ;Subramanya (2002)

Where $\mathrm{n}=$ number of events, $\mathrm{m}=$ Ranking order of rainfall event magnitude 


\subsection{Study Area}

\section{MATERIALS AND METHODS}

The study area lies between longitude $7^{\circ} 50^{\prime} 9.51 \mathrm{E}$ to $8^{\circ} 6^{\prime} 17.25 \mathrm{E}$ east of the meridian, and latitude $5^{\circ} 9^{\prime} 32.36 \mathrm{~N}$ to $4^{\circ} 58^{\prime} 9.28 \mathrm{~N}$ of the equator an average elevation of $52.705 \mathrm{~m}$ above sea level as shown in Figures 1 and 2 while Figures 3 - 5 shows the drainage pattern, watershed sub catchment delineation and the Digital Elevation Model (DEM) of the study area. The study area watershed cut across three Local Government Areas of Akwa Ibom which are Itu, Uyo and Uruan with an estimated basin area of $360.563 \mathrm{~km}^{2}$ and total length of stream of about $158.23 \mathrm{~km}$. This lies within the equatorial rain forest belt, which is a tropical zone that house vegetation of green foliage of trees shrubs and oil palm trees. A considerable area of the watershed is built-up and still under construction and expansion. The climate of the watershed is a tropical rainy type which experiences abundant rainfall with very high temperature. The mean annual temperature recorded lies between $20^{\circ} \mathrm{C}$ and $29^{\circ} \mathrm{C}$ and average sunshine accumulates to 1450 hours per year. The rainfall distribution pattern is seasonal, convectional and spatial. Uyo mean annual rainfall ranges from $1599 \mathrm{~mm}$ to $3855 \mathrm{~mm}$. maximum humidity is recorded in July while minimum humidity occurs in January. Thick cloud is cumoni cumulonimbus type is commonly experienced in the months of March to November. Evaporation is high and annual values range from $1500 \mathrm{~mm}$ to $1800 \mathrm{~mm}$, AKSG, (2008). Major activities in the watershed are educational and farming.

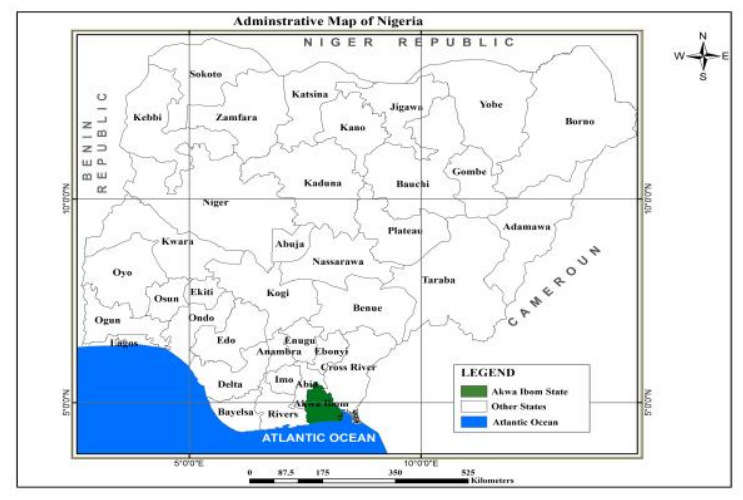

Figure 1: Map of Nigeria Showing Akwa Ibom State

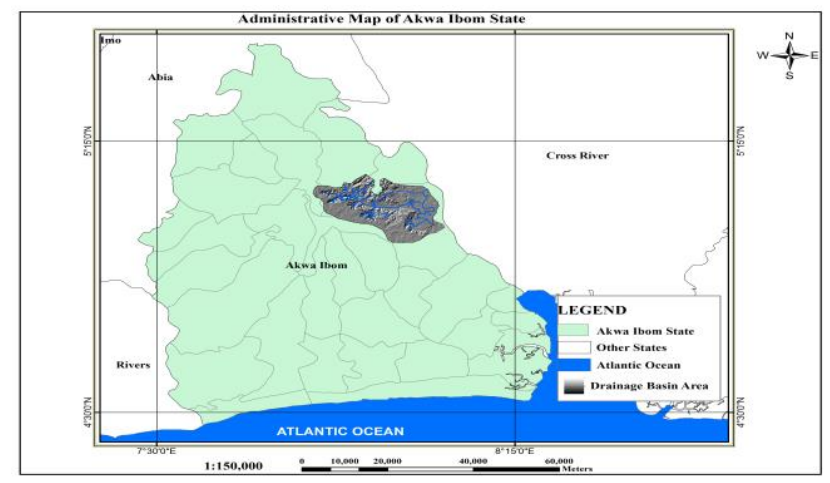

Figure 2: Map of Akwa Ibom Showing the study watershed Area within Ikpa River Basin

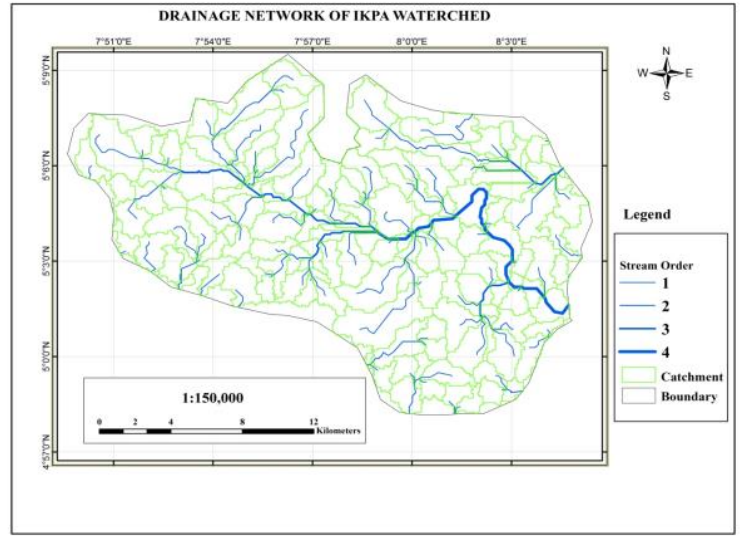

Figure 3: Drainage Pattern of the study Area watershed

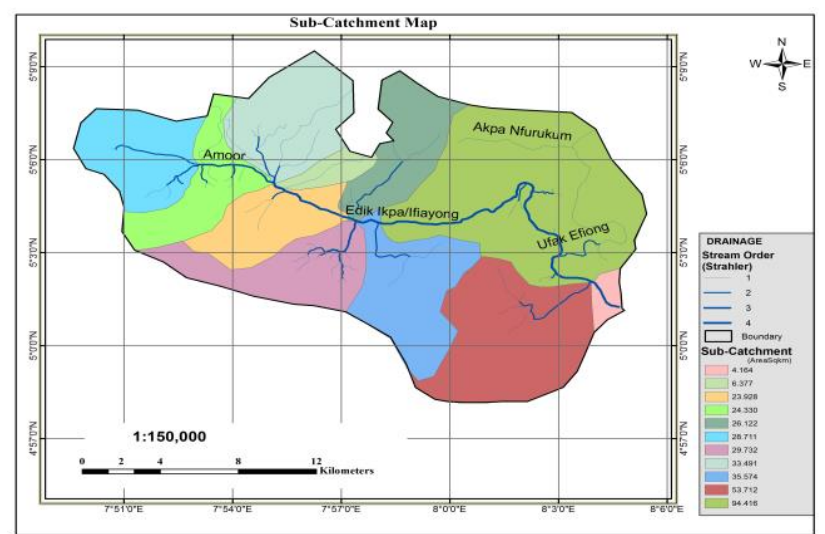

Figure 4: Catchment delineation of the study Area Watershed

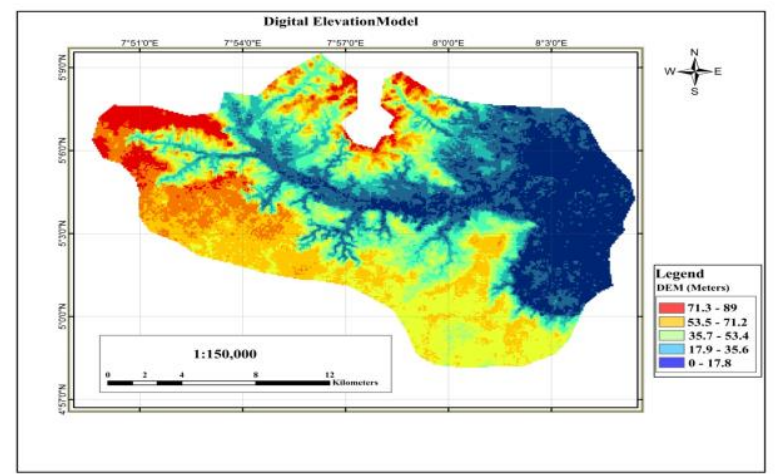

Figure 5: Digital Elevation Model (DEM) of the study Area Watershed 


\subsection{Material and Method}

Rainfall data was obtained from the Nigerian Meteorological Agency (NIMET), Abuja Nigeria for the studied watershed covering 33years from 1983 - 2013 The obtained rainfall data from NIMET was analysed. The annual total, annual mean, annual maximum, annual minimum, annual standard deviation, annual variance, and annual coefficient of variation values were determined using Ms Excel (2007) software. The annual mean values were then sorted in descending order of magnitudes. Using the plotting positions of Weibull, California and Hazen respectively, the observed rainfall magnitudes for each of these plotting positions were obtained ( for 1981 to 2013) as well as the predicted rainfall magnitudes for the corresponding return periods of $1.25,2,5,10,20,50$ and 100 years respectively using equations $4-8$. The determination of confidence limits and goodness of fit was not done since the research was designed to determine exactly which of the commonly used hydrological probability distributions is best suitable for this region as determination of confidence limits and goodness of fit had already been done by previous works cited above (Olafintoye, et al (2009); Dike and Nwachukwu (2003); Okonkwo and Mbajiorgu (2010)). The purpose was to select the best probability distribution(s) from the list given for the region by previous researchers which perfectly is suited for this research area and predict the rainfall magnitudes for return periods of 1.25, 2, 5, 10, 20, 50 and 100years.

\section{RESULT AND DISCUSSION}

From the analysis, it was observed that 2012 has the highest mean rainfall (mm), followed by 2013, 2011 while 1983, 1997 and 1986 had the least mean rainfall (mm) values of $128.49,139.44$ and $146.91 \mathrm{~mm}$ in that order. The values for each plotting positions as obtained from the computation were recorded as observed rainfall for the three plotting positions as shown in Table 2. The result obtained from the analysis shows that California and Hazen plotting positions are best fitted to the Log Normal probability distribution for the rainfall of the studied area while the Weibull plotting position showed a deviation when the values where plotted using Microsoft Excel 2007. The resulted graphs when these values were plotted are shown in Figures $6 \mathrm{a}-\mathrm{c}$ for comparison purpose.

Figures $6 \mathrm{~b}$ and $6 \mathrm{c}$ were similar in shape while Figure $6 \mathrm{a}$ deviated significantly from the graphs obtained when Hazen and California plotting positions values were plotted against their various observed rainfall magnitudes. This suggests that for Log Normal distribution, the Hazen and California plotting positions perfectly best fitted the observed rainfall magnititude obtained.

Table 2. Log-Normal (LN) Distribution with the Plotting Positions

\begin{tabular}{|c|c|c|c|c|c|c|c|c|}
\hline $\mathbf{S} / \mathbf{N}$ & $\begin{array}{c}\text { Year } \\
\text { (sorted) }\end{array}$ & $\begin{array}{c}\text { Mean Rainfall } \\
(\mathbf{m m})\end{array}$ & $\begin{array}{c}\text { Return } \\
\text { Period } \\
\text { (TR) }\end{array}$ & $\begin{array}{c}\text { Weibull } \\
\text { Observed } \\
(\mathbf{m m})\end{array}$ & $\begin{array}{c}\text { Return } \\
\text { Period } \\
\text { (TR) }\end{array}$ & $\begin{array}{c}\text { Hazen } \\
\text { Observed } \\
(\mathbf{m m})\end{array}$ & $\begin{array}{c}\text { Return } \\
\text { Period } \\
\text { (TR) }\end{array}$ & $\begin{array}{c}\text { California } \\
\text { Observed } \\
(\mathrm{mm})\end{array}$ \\
\hline 1. & 2012 & 385.56 & 1.03 & 113.20 & 1.02 & 128.04 & 33.0 & 304.3 \\
\hline 2. & 2013 & 350.40 & 1.06 & 115.80 & 1.05 & 137.10 & 16.5 & 281.7 \\
\hline 3. & 2011 & 331.87 & 1.10 & 119.20 & 1.08 & 143.17 & 11.0 & 268.5 \\
\hline 4. & 1996 & 225.56 & 1.13 & 121.50 & 1.12 & 149.33 & 8.25 & 253.4 \\
\hline 5. & 2007 & 222.56 & 1.17 & 124.50 & 1.16 & 154.26 & 6.60 & 250.2 \\
\hline 6. & 1994 & 221.47 & 1.21 & 127.30 & 1.20 & 158.40 & 5.50 & 243.3 \\
\hline 8. & 1995 & 207.48 & 1.31 & 133.80 & 1.29 & 166.02 & 4.12 & 231.8 \\
\hline 9. & 1989 & 207.16 & 1.36 & 136.70 & 1.35 & 170.19 & 3.67 & 226.8 \\
\hline 10. & 1985 & 206.63 & 1.47 & 140.00 & 1.40 & 173.30 & 3.30 & 222.2 \\
\hline 11. & 2006 & 206.32 & 1.48 & 143.10 & 1.47 & 177.17 & 3.00 & 217.9 \\
\hline 12. & 2010 & 201.00 & 1.55 & 146.60 & 1.53 & 180.20 & 2.75 & 213.8 \\
\hline 13. & 1981 & 200.78 & 1.62 & 149.80 & 1.61 & 183.76 & 2.54 & 209.9 \\
\hline 14. & 1991 & 198.69 & 1.70 & 153.20 & 1.69 & 187.00 & 2.36 & 206.2 \\
\hline 15. & 2004 & 197.32 & 1.79 & 156.90 & 1.78 & 190.31 & 2.20 & 202.5 \\
\hline 17. & 2001 & 192.28 & 2.00 & 211.30 & 2.00 & 197.20 & 1.94 & 195.5 \\
\hline 18. & 2003 & 191.53 & 2.13 & 219.90 & 2.13 & 200.75 & 1.83 & 192.0 \\
\hline 19. & 1999 & 190.96 & 2.27 & 228.69 & 2.28 & 204.39 & 1.74 & 188.9 \\
\hline 20. & 1992 & 188.17 & 2.43 & 238.25 & 2.44 & 207.89 & 1.65 & 184.6 \\
\hline 21. & 1990 & 187.83 & 2.62 & 249.02 & 2.64 & 211.79 & 1.57 & 182.0 \\
\hline 22. & 1988 & 186.57 & 2.83 & 260.32 & 2.87 & 215.79 & 1.50 & 178.7 \\
\hline 23. & 1993 & 184.35 & 3.09 & 273.54 & 3.14 & 219.94 & 1.44 & 175.6 \\
\hline 24. & 2008 & 184.23 & 3.40 & 288.40 & 3.47 & 224.40 & 1.36 & 170.8 \\
\hline 25. & 1987 & 180.37 & 3.78 & 305.49 & 3.88 & 229.19 & 1.32 & 168.9 \\
\hline 26. & 1982 & 179.62 & 4.25 & 325.24 & 4.40 & 234.40 & 1.27 & 168.2 \\
\hline 27. & 1998 & 168.39 & 4.86 & 349.02 & 5.08 & 240.20 & 1.22 & 164.5 \\
\hline 28. & 2000 & 167.02 & 5.67 & 378.06 & 6.00 & 246.60 & 1.18 & 160.3 \\
\hline 29. & 2009 & 159.28 & 6.80 & 414.90 & 7.33 & 254.10 & 1.14 & 156.4 \\
\hline 30. & 1984 & 152.93 & 8.50 & 464.24 & 9.43 & 263.10 & 1.10 & 151.9 \\
\hline 31. & 1986 & 146.91 & 11.38 & 535.57 & 13.20 & 274.70 & 1.07 & 146.5 \\
\hline 32. & 1997 & 139.44 & 17.00 & 653.50 & 22.00 & 291.50 & 1.03 & 141.3 \\
\hline 33. & 1983 & 128.49 & 34.00 & 913.76 & 66.00 & 325.32 & 1.00 & 137.1 \\
\hline
\end{tabular}




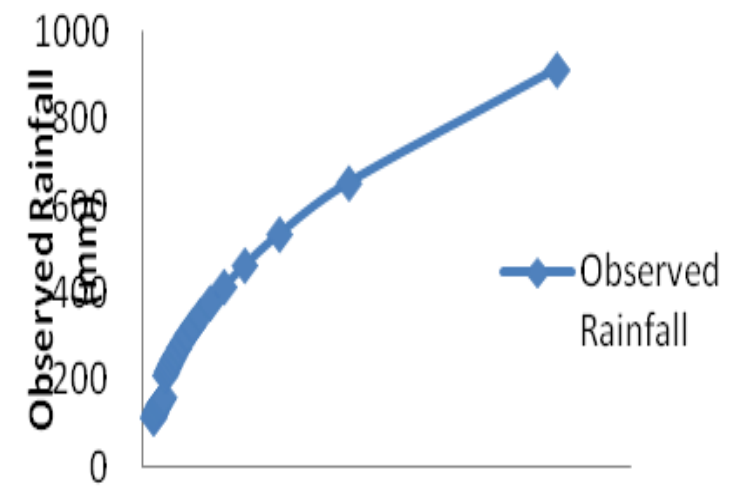

\section{$0 \quad$ Return Period (yis's) 40}

Figure 6a: Graph of Log Normal Distribution against Retun Period for Weibull Plotting Position

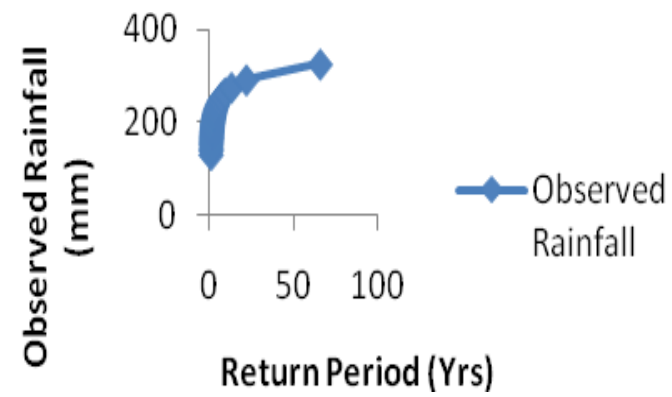

Figure 6b: Graph of Log Normal Distribution against Retun Period for Hazen Plotting Position.

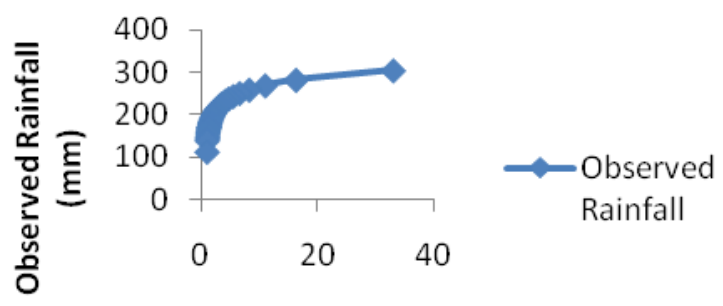

Return Period (yrs)

Figure 6c: Graph of Log Normal Distribution against Retun Period for California Plotting Position.

Table 3: Pearson Type III (PT3) Distribution with the Plotting Positions

\begin{tabular}{|c|c|c|c|c|c|c|c|c|}
\hline $\mathbf{S} / \mathbf{N}$ & $\begin{array}{c}\text { Year } \\
\text { (sorted) }\end{array}$ & $\begin{array}{c}\text { Mean Rainfall } \\
\text { (mm) }\end{array}$ & $\begin{array}{c}\text { Return } \\
\text { Period } \\
\text { (TR) }\end{array}$ & $\begin{array}{c}\text { Weibull } \\
\text { Observed } \\
(\mathrm{mm})\end{array}$ & $\begin{array}{c}\text { Return } \\
\text { Period } \\
\text { (TR) }\end{array}$ & $\begin{array}{c}\text { Hazen } \\
\text { Observed } \\
(\mathbf{m m}) \\
\end{array}$ & $\begin{array}{c}\text { Return } \\
\text { Period } \\
\text { (TR) }\end{array}$ & $\begin{array}{c}\text { California } \\
\text { Observed } \\
(\mathrm{mm})\end{array}$ \\
\hline 1. & 2012 & 385.56 & 1.03 & 75.01 & 1.02 & 46.15 & 33.0 & -80.86 \\
\hline 2. & 2013 & 350.40 & 1.06 & 105.43 & 1.05 & 94.27 & 16.5 & 76.34 \\
\hline 3. & 2011 & 331.87 & 1.10 & 122.14 & 1.08 & 116.01 & 11.0 & 106.70 \\
\hline 4. & 1996 & 225.56 & 1.13 & 133.10 & 1.12 & 129.25 & 8.25 & 123.32 \\
\hline 5. & 2007 & 222.56 & 1.17 & 140.99 & 1.16 & 138.38 & 6.60 & 134.19 \\
\hline 6. & 1994 & 221.47 & 1.21 & 147.02 & 1.20 & 145.17 & 5.50 & 142.00 \\
\hline 7. & 2005 & 218.43 & 1.26 & 151.86 & 1.25 & 150.49 & 4.71 & 147.97 \\
\hline 8. & 1995 & 207.48 & 1.31 & 155.89 & 1.29 & 154.86 & 4.12 & 152.77 \\
\hline 9. & 1989 & 207.16 & 1.36 & 159.38 & 1.35 & 158.58 & 3.67 & 156.78 \\
\hline 10. & 1985 & 206.63 & 1.47 & 162.50 & 1.40 & 161.86 & 3.30 & 160.26 \\
\hline 11. & 2006 & 206.32 & 1.48 & 165.38 & 1.47 & 164.87 & 3.00 & 163.39 \\
\hline 12. & 2010 & 201.00 & 1.55 & 168.11 & 1.53 & 167.70 & 2.75 & 166.30 \\
\hline 13. & 1981 & 200.78 & 1.62 & 170.78 & 1.61 & 170.45 & 2.54 & 169.08 \\
\hline 14. & 1991 & 198.69 & 1.70 & 173.45 & 1.69 & 173.20 & 2.36 & 171.82 \\
\hline 15. & 2004 & 197.32 & 1.79 & 176.18 & 1.78 & 176.01 & 2.20 & 174.59 \\
\hline
\end{tabular}

On analysis with Pearson Type III (PT3), results obtained showed that observed values returned for each plotting positions used increases in magnitude to decreasing magnitude of the mean rainfall values obtained from NIMET. That is when the mean values for years 2012, 2013 and 2011 are $385.56 \mathrm{~mm}, 350.40 \mathrm{~mm}$ and $331.87 \mathrm{~mm}$ respectively, their corresponding computed observed values for Weibull plotting position were $75.01 \mathrm{~mm}$, $105.43 \mathrm{~mm}$ and $122.14 \mathrm{~mm}$; for Hazen plotting position, $46.15 \mathrm{~mm}, 94.27 \mathrm{~mm}$ and $116.01 \mathrm{~mm}$ were obtained. While California plotting position showed a negative value (-80.86 $\mathrm{mm})$ for the observed rainfall value corresponding to the highest mean rainfall of $385.56 \mathrm{~mm}$ with $76.34 \mathrm{~mm}$ and $106.70 \mathrm{~mm}$ for the year 2013 and 2011. The negative value recorded in Califiornia plotting position influenced the nature of the graph generated making it deviate from the normal shape and accounts for it not fitting to the distribution.. For the last three least values of the mean rainfall as obtained from NIMET, the corresponding observed values for the three plotting positions, namely Weibull, Hazen and California were $463.30 \mathrm{~mm}, 562.07$ $\mathrm{mm}$ and 459.11 for 1983 with mean rainfall value of $128.49 \mathrm{~mm} ; 371.72 \mathrm{~mm}, 404.31 \mathrm{~mm}$ and $368.06 \mathrm{~mm}$ for year 1997 with mean rainfall of $139.44 \mathrm{~mm}$. while for year 1986 with a mean rainfall value of $146.91 \mathrm{~mm}$ has 324.24 $\mathrm{mm}, 341.53 \mathrm{~mm}$ and $320.94 \mathrm{~mm}$ for Weibull, Hazen and California plotting positions. The values so obtained seem to be decreasing for each of the plotting positions when the corresponding value for the mean rainfall is increasing. This is clearly seen in the obtained observed values shown in Table 3 below. 


\begin{tabular}{|c|c|c|c|c|c|c|c|c|}
\hline 16. & 2002 & 192.98 & 1.89 & 179.02 & 1.89 & 178.94 & 2.06 & 177.45 \\
\hline 17. & 2001 & 192.28 & 2.00 & 182.05 & 2.00 & 182.05 & 1.94 & 180.47 \\
\hline 18. & 2003 & 191.53 & 2.13 & 185.31 & 2.13 & 185.41 & 1.83 & 183.69 \\
\hline 19. & 1999 & 190.96 & 2.27 & 188.86 & 2.28 & 189.09 & 1.74 & 187.21 \\
\hline 20. & 1992 & 188.17 & 2.43 & 192.80 & 2.44 & 193.17 & 1.65 & 191.08 \\
\hline 21. & 1990 & 187.83 & 2.62 & 197.18 & 2.64 & 197.75 & 1.57 & 195.39 \\
\hline 22. & 1988 & 186.57 & 2.83 & 202.13 & 2.87 & 202.94 & 1.50 & 200.26 \\
\hline 23. & 1993 & 184.35 & 3.09 & 207.77 & 3.14 & 208.88 & 1.44 & 205.81 \\
\hline 24. & 2008 & 184.23 & 3.40 & 214.27 & 3.47 & 215.78 & 1.36 & 212.20 \\
\hline 25. & 1987 & 180.37 & 3.78 & 221.85 & 3.88 & 223.88 & 1.32 & 219.66 \\
\hline 26. & 1982 & 179.62 & 4.25 & 230.81 & 4.40 & 233.54 & 1.27 & 228.49 \\
\hline 27. & 1998 & 168.39 & 4.86 & 241.58 & 5.08 & 245.30 & 1.22 & 239.12 \\
\hline 28. & 2000 & 167.02 & 5.67 & 254.82 & 6.00 & 259.94 & 1.18 & 252.19 \\
\hline 29. & 2009 & 159.28 & 6.80 & 271.55 & 7.33 & 278.81 & 1.14 & 268.73 \\
\hline 30. & 1984 & 152.93 & 8.50 & 293.54 & 9.43 & 304.31 & 1.10 & 290.50 \\
\hline 31. & 1986 & 146.91 & 11.38 & 324.24 & 13.20 & 341.53 & 1.07 & 320.94 \\
\hline 32. & 1997 & 139.44 & 17.00 & 371.72 & 22.00 & 404.31 & 1.03 & 368.06 \\
\hline 33. & 1983 & 128.49 & 34.00 & 463.30 & 66.00 & 562.07 & 1.00 & 459.11 \\
\hline
\end{tabular}

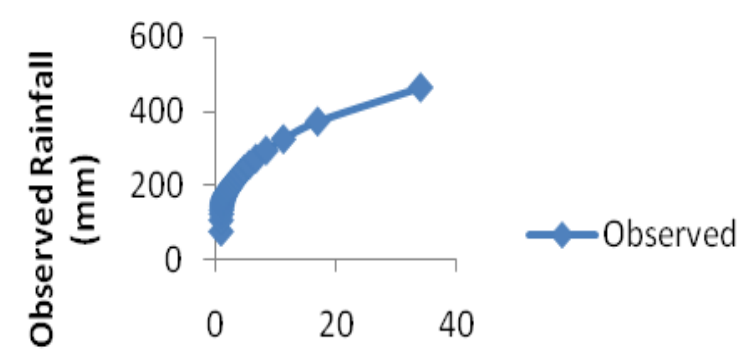

Return Period (yrs)

Figure 7a: Graph of Pearson Type III Distribution against Retun Period for Weibull Plotting Position.

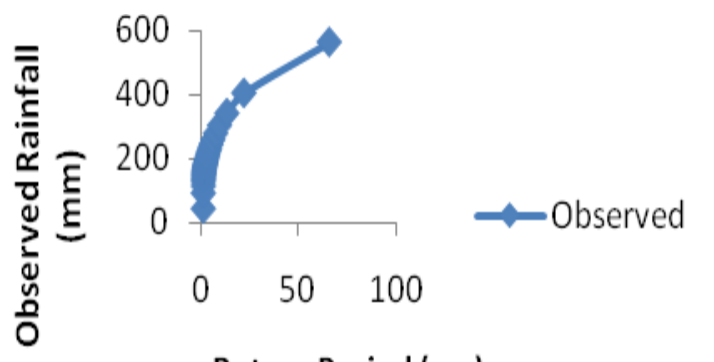

Return Period (yrs)

Figure 7b: Graph of Pearson Type III Distribution against Retun Period for Hazen Plotting Position.

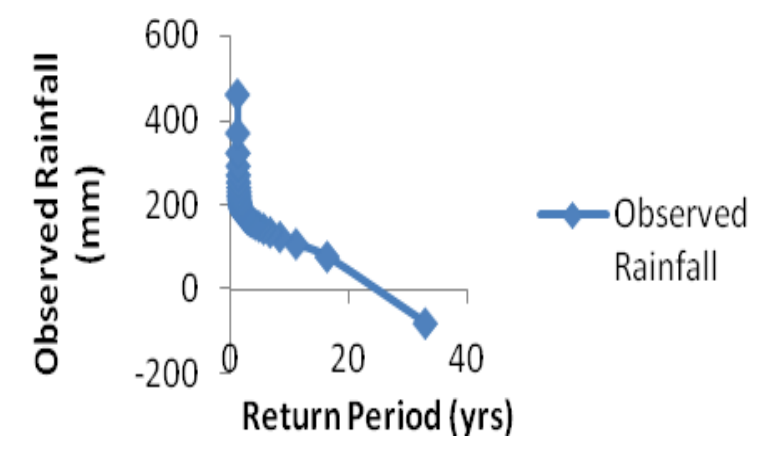

Figure 7c: Graph of Pearson Type III Distribution against Retun Period for California Plotting Position.
When the obtained observed values for the three different plotting positions were plotted on a normal graph for the computed return periods, Weibull and Hazen assume a similar shape indicating that both best suit Pearson distribution for the computed watershed observed rainfall values, see Figures $7 \mathrm{a}$ and $7 \mathrm{~b}$. California plotting positions deviated significantly from the other two suggesting that it is not suited for the watershed rainfall data, analysing with Pearson Type III as shown in Figure 7c.

Following the same approach in the computation of the observed rainfall values for the studied area, adopting the extreme value type I distribution (EVT I), it was observed that California plotting position recorded zero value for return period of 1 corresponding to the lowest mean rainfall data for the year 1983 when it was sorted in descending order of magnitude. However, it started returning observed rainfall values in increasing/ascending order of magnitude. However, it started returning observed rainfall values in increasing/ascending order of magnitude corresponding to decreasing/descending order of rainfall magnitude for the measured mean rainfall obtained from NIMET. For the years 2012, 2013 and 2011 respectively, according to their sorted descending magnitude for the measured mean rainfall values obtained from NIMET, Weibull plotting position recorded a corresponding ascending observed rainfall values, in millimeter, of 115.39, 126.07 and 133.60 for the years specified; Hazen plotting position had 106.99, 121.82 and 130.63 while California had 346.53, 312.02 and 291.46, as shown in Table 4. While the measured mean rainfall obtained from NIMET for the years 1986, 1997 and 1983 had the lowest in range of values in that order of years, the three plotting positions had an approximate corresponding values in increasing order of magnitude of, for Weibull: $292.99 \mathrm{~mm}, 313.52 \mathrm{~mm}$ and $348.06 \mathrm{~mm}$; Hazen: $300.75 \mathrm{~mm}, 326.43 \mathrm{~mm}$ and $380.76 \mathrm{~mm}$ and for California: $126.58 \mathrm{~mm}, 115.81 \mathrm{~mm}$ and $0 \mathrm{~mm}$ respectively. When the values obtained for the observed rainfall for the thirty-three (33) years rainfall data obtained from NIMET were plotted for three plotting positions as shown in Figures $8 \mathrm{a}-\mathrm{c}$., Weibull, Hazen and California graphs all approximated the EVT I distribution suggesting that the three distributions perfectly best fitted the EVT I distribution. 
Table 4: Extreme Value Type 1 (EVT1 - Gumbel) Distribution with the Plotting Positions

\begin{tabular}{|c|c|c|c|c|c|c|c|c|}
\hline $\mathbf{S} / \mathbf{N}$ & $\begin{array}{c}\text { Year } \\
\text { (sorted) }\end{array}$ & $\begin{array}{c}\text { Mean Rainfall } \\
(\mathrm{mm})\end{array}$ & $\begin{array}{c}\text { Return } \\
\text { Period } \\
\text { (TR) } \\
\end{array}$ & $\begin{array}{c}\text { Weibull } \\
\text { Observed } \\
(\mathrm{mm})\end{array}$ & $\begin{array}{c}\text { Return } \\
\text { Period } \\
\text { (TR) }\end{array}$ & $\begin{array}{c}\text { Hazen } \\
\text { Observed } \\
(\mathrm{mm})\end{array}$ & $\begin{array}{c}\text { Return } \\
\text { Period } \\
\text { (TR) }\end{array}$ & $\begin{array}{c}\text { California } \\
\text { Observed } \\
(\mathrm{mm})\end{array}$ \\
\hline 1. & 2012 & 385.56 & 1.03 & 115.39 & 1.02 & 106.99 & 33.0 & 346.58 \\
\hline 2. & 2013 & 350.40 & 1.06 & 126.07 & 1.05 & 121.82 & 16.5 & 312.02 \\
\hline 3. & 2011 & 331.87 & 1.10 & 133.60 & 1.08 & 130.63 & 11.0 & 291.46 \\
\hline 4. & 1996 & 225.56 & 1.13 & 139.75 & 1.12 & 137.44 & 8.25 & 276.62 \\
\hline 5. & 2007 & 222.56 & 1.17 & 145.12 & 1.16 & 143.23 & 6.60 & 264.91 \\
\hline 6. & 1994 & 221.47 & 1.21 & 149.99 & 1.20 & 148.41 & 5.50 & 255.16 \\
\hline 7. & 2005 & 218.43 & 1.26 & 154.53 & 1.25 & 153.18 & 4.71 & 246.75 \\
\hline 8. & 1995 & 207.48 & 1.31 & 158.83 & 1.29 & 157.68 & 4.12 & 239.33 \\
\hline 9. & 1989 & 207.16 & 1.36 & 162.97 & 1.35 & 161.98 & 3.67 & 232.64 \\
\hline 10. & 1985 & 206.63 & 1.47 & 167.00 & 1.40 & 166.15 & 3.30 & 226.52 \\
\hline 11. & 2006 & 206.32 & 1.48 & 170.95 & 1.47 & 170.24 & 3.00 & 220.86 \\
\hline 12. & 2010 & 201.00 & 1.55 & 174.87 & 1.53 & 174.27 & 2.75 & 215.56 \\
\hline 13. & 1981 & 200.78 & 1.62 & 178.76 & 1.61 & 178.29 & 2.54 & 210.57 \\
\hline 14. & 1991 & 198.69 & 1.70 & 182.67 & 1.69 & 182.32 & 2.36 & 205.81 \\
\hline 15. & 2004 & 197.32 & 1.79 & 186.62 & 1.78 & 186.38 & 2.20 & 201.26 \\
\hline 16. & 2002 & 192.98 & 1.89 & 190.63 & 1.89 & 190.50 & 2.06 & 196.86 \\
\hline 17. & 2001 & 192.28 & 2.00 & 194.71 & 2.00 & 194.71 & 1.94 & 192.60 \\
\hline 18. & 2003 & 191.53 & 2.13 & 198.91 & 2.13 & 199.04 & 1.83 & 188.43 \\
\hline 19. & 1999 & 190.96 & 2.27 & 203.24 & 2.28 & 203.51 & 1.74 & 184.34 \\
\hline 20. & 1992 & 188.17 & 2.43 & 207.47 & 2.44 & 208.16 & 1.65 & 180.30 \\
\hline 21. & 1990 & 187.83 & 2.62 & 212.45 & 2.64 & 213.03 & 1.57 & 176.28 \\
\hline 22. & 1988 & 186.57 & 2.83 & 217.40 & 2.87 & 218.17 & 1.50 & 172.26 \\
\hline 23. & 1993 & 184.35 & 3.09 & 222.65 & 3.14 & 223.64 & 1.44 & 168.20 \\
\hline 24. & 2008 & 184.23 & 3.40 & 228.27 & 3.47 & 229.52 & 1.36 & 164.08 \\
\hline 25. & 1987 & 180.37 & 3.78 & 234.35 & 3.88 & 235.90 & 1.32 & 159.85 \\
\hline 26. & 1982 & 179.62 & 4.25 & 241.00 & 4.40 & 242.94 & 1.27 & 155.46 \\
\hline 27. & 1998 & 168.39 & 4.86 & 248.39 & 5.08 & 250.81 & 1.22 & 150.83 \\
\hline 28. & 2000 & 167.02 & 5.67 & 256.77 & 6.00 & 259.83 & 1.18 & 145.88 \\
\hline 29. & 2009 & 159.28 & 6.80 & 266.49 & 7.33 & 270.46 & 1.14 & 140.43 \\
\hline 30. & 1984 & 152.93 & 8.50 & 278.17 & 9.43 & 283.54 & 1.10 & 134.20 \\
\hline 31. & 1986 & 146.91 & 11.38 & 292.99 & 13.20 & 300.75 & 1.07 & 126.58 \\
\hline 32. & 1997 & 139.44 & 17.00 & 313.52 & 22.00 & 326.43 & 1.03 & 115.81 \\
\hline 33. & 1983 & 128.49 & 34.00 & 348.06 & 66.00 & 380.76 & 1.00 & - \\
\hline
\end{tabular}

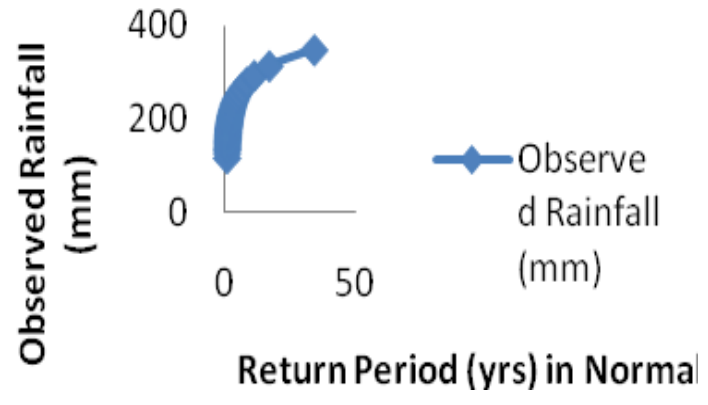

Figure 8a: Graph of Extreme Value Type I - Gumbel (EVT I) Distribution against Retun Period for Weibull Plotting Position.

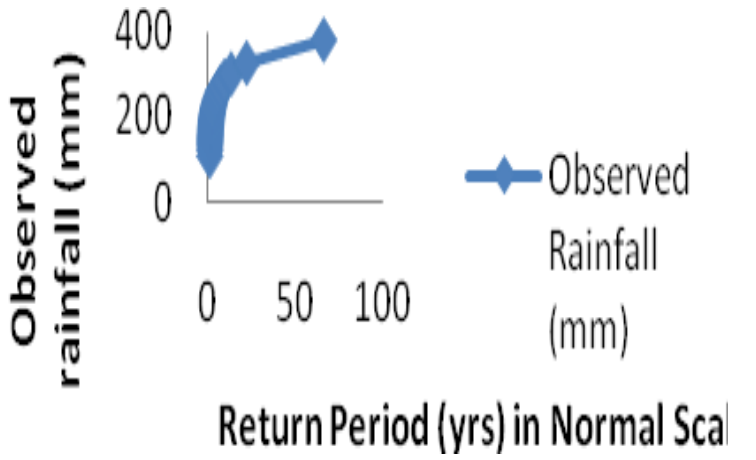

Figure 8b: Graph of Extreme Value Type I - Gumbel (EVT I) Distribution against Retun Period for Hazen Plotting Position. 


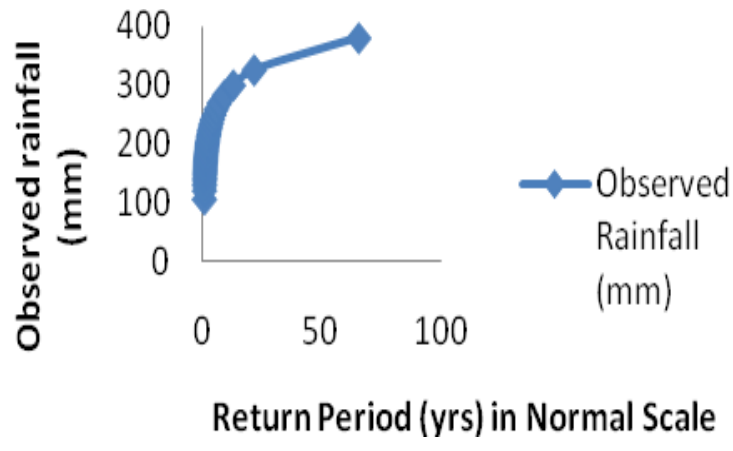

Figure 8c: Graph of Extreme Value Type I - Gumbel (EVT I) Distribution against Retun Period for California Plotting Position.

It was observed from the analysis of the rainfall data obtained for the studied area that Hazen plotting position perfectly best fitted the three adopted probability distributions used. One could also conclude from finding that the order of fitting perfectly to the three probability distributions of Log Normal, Pearson Type III (PT 3) and Extreme Value Type I - Gumbel (EVT I) into the three plotting positions used is in the increasing order: Hazen > Weibull > California. This affirms the earlier positions of other researcher like Okonkwo and Mbajiorgu (2010),
Olafintoye et al (2009), Dike and Okonkwo (2003) and Ologhadien and Nwaogazie (2014) who have worked on fitting the rainfall data of this region (South South, Nigeria) to the various adopted probability distributions using these plotting positions without particular emphasis on the study area in this research.

The obtained rainfall data from NIMET spanning thirty three years was also used in predicting the rainfall magnitude for the studied area using the three probability distributions for return periods of 1.25years, 2years, 5years, 10years, 20years, 50years and 100years respectively. The results obtained for each of the mentioned years for the various probability distributions are as shown in Table 5 below. Log Normal distribution showed an increased value in predicted rainfall magnitude recording a value of $186.266 \mathrm{~mm}$ as against corresponding low value of $150.347 \mathrm{~mm}$ and $153.640 \mathrm{~mm}$ for Pearson Type III and Extreme Value Type I (Gumbel) distributions respectively. Thereafter, the values of the three probabilities considered started increasing relatively to a corresponding increase in return periods in years as seen in Table 5 till the return period of ten (10) years when the three probabilities distributions considered could be said to be approximate in the values of rainfall magnitude $(\mathrm{mm})$ perdicted.

Table 5: The Three Distributions with Results of Predicted Rainfall Magnitudes (mm)

\begin{tabular}{ccccc}
\hline S/N & $\begin{array}{c}\text { RETURN PREIOD } \\
\text { (YRS) }\end{array}$ & $\begin{array}{c}\text { LOG-NORMAL } \\
(\text { LN) }\end{array}$ & $\begin{array}{c}\text { PEARSON TYPE 3 } \\
\text { (PT3) }\end{array}$ & $\begin{array}{c}\text { EXTREME VALUE } \\
\text { TYPE 1 (EVT1) }\end{array}$ \\
\hline 1. & 1.25 & 186.266 & 150.347 & 153.640 \\
2. & 2.00 & 197.432 & 150.726 & 194.714 \\
3. & 5.00 & 239.787 & 224.000 & 249.980 \\
4. & 10.00 & 265.454 & 295.930 & 286.570 \\
5. & 20.00 & 288.702 & 372.302 & 321.669 \\
6. & 50.00 & 317.303 & 478.239 & 367.100 \\
7. & 100.00 & 337.924 & 561.038 & 401.144 \\
\hline
\end{tabular}

Pearson type III, afterward started showing a higher increased value in predicted rainfall magnitude from 20years till 100years with a corresponding values of $372.302 \mathrm{~mm}$ and $561.038 \mathrm{~mm}$ respectively. This is followed by Gumbel distribution recording corresponding values for the same years (i.e 20 and 100) of $321.669 \mathrm{~mm}$ and $401.144 \mathrm{~mm}$ while Log Normal had the least increasing values for the same predicted years of 20years and 100years as $288.702 \mathrm{~mm}$ and $337.924 \mathrm{~mm}$ respectively. These values are plotted on graphs (10, 11, and 12) below.

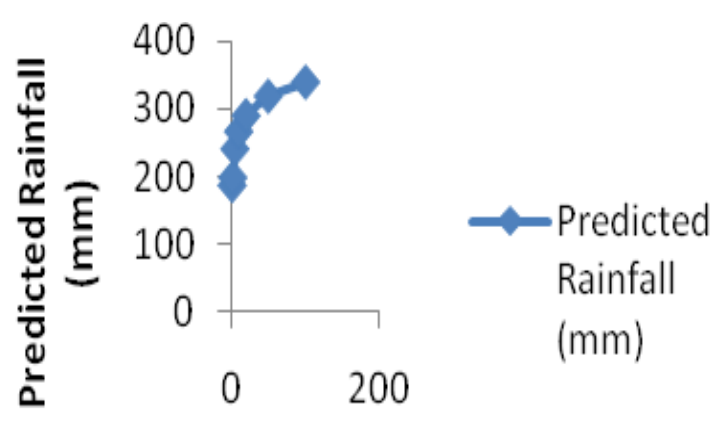

Return Period (yrs)

Figure 10: Graph of Log Normal distribution for the predicted rainfall data for $1.25-100 \mathrm{yrs}$ 


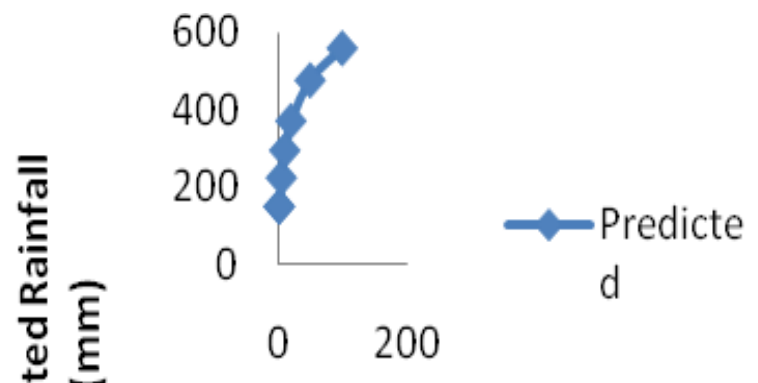

\section{Return Period (yrs)}

Figure 11: Graph of Pearson Type III distribution for the predicted rainfall data for $1.25-100 \mathrm{yrs}$

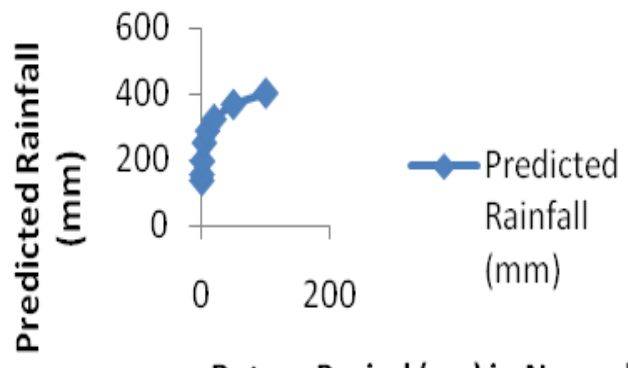

Return Period (yrs) in Normal S
Figure 12: Graph of Gumbel distribution for the predicted rainfall data for $1.25-100 \mathrm{yrs}$

From Table 6 result, the year 1983 has the least annual total rainfall magnitude of $1541.9 \mathrm{~mm}$ with a mean value of $128.49 \mathrm{~mm}$. The maximum rainfall value recorded for the same year was $313.70 \mathrm{~mm}$ with a standard deviation (SD) value of 101.8412 and coefficient of variation of 0.324645 . The year with the highest rainfall was 2012 recording a total annual rainfall value of 4626.70 and a mean rainfall value of $385.56 \mathrm{~mm}$. The maximum recorded rainfall value for the same year was $911.90 \mathrm{~mm}$ with a standard deviation value of 289.4497 and coefficient of variation of 0.370180 . The range between these two extreme values is, based on average recorded value is 257.07. This signifies that year 2012 was the wettest year for the period used in this analysis while year 1983 was the driest. The highest minimum value recorded within the years of data used in this study was $28.60 \mathrm{~mm}$ against the year 2013 while the least minimum values other than $28.60 \mathrm{~mm}$ were recorded in ten other years. The remaining twenty - three years obviously had zero as their minimum rainfall magnitude.

Table 6: Statistical Analysis of the Rainfall Magnitude (mm) according to years $(1981-2013)$

\begin{tabular}{|c|c|c|c|c|c|c|c|c|}
\hline $\mathbf{S} / \mathbf{N}$ & Year & Annual Total & Mean & Max & Min & SD & Vari & Coeff. Var \\
\hline 1 & 1981 & 2409.4 & 200.78 & 438.9 & 0.0 & 158.9158 & 25254.23 & 0.362077 \\
\hline 2 & 1982 & 2155.4 & 179.62 & 340.0 & 4.7 & 122.1681 & 14925.03 & 0.359318 \\
\hline 3 & 1983 & 1541.9 & 128.49 & 313.7 & 0.0 & 101.8412 & 10371.62 & 0.324645 \\
\hline 4 & 1984 & 1835.1 & 152.93 & 389.5 & 0.0 & 121.8856 & 14856.09 & 0.312928 \\
\hline 5 & 1985 & 2480.2 & 206.68 & 462.0 & 0.0 & 143.2853 & 20530.68 & 0.310141 \\
\hline 6 & 1986 & 1762.9 & 146.91 & 354.2 & 0.0 & 114.732 & 13163.43 & 0.323919 \\
\hline 7 & 1987 & 2164.4 & 180.37 & 409.8 & 0.0 & 135.5756 & 18380.73 & 0.330833 \\
\hline 8 & 1988 & 2238.8 & 186.57 & 565.6 & 3.5 & 169.1083 & 28597.61 & 0.298989 \\
\hline 9 & 1989 & 2485.9 & 207.16 & 574.2 & 0.0 & 196.739 & 38706.23 & 0.342631 \\
\hline 10 & 1990 & 2253.9 & 187.83 & 551.9 & 0.3 & 174.2671 & 30369.04 & 0.315759 \\
\hline 11 & 1991 & 2384.3 & 198.69 & 378.9 & 0.0 & 150.1887 & 22556.64 & 0.396381 \\
\hline 12 & 1992 & 2258.0 & 188.17 & 495.6 & 0.0 & 158.9203 & 25255.66 & 0.320662 \\
\hline 13 & 1993 & 2212.2 & 184.35 & 429.6 & 2.6 & 140.1336 & 19637.43 & 0.326196 \\
\hline 14 & 1994 & 2657.6 & 221.47 & 534.5 & 0.0 & 181.7142 & 33020.06 & 0.339970 \\
\hline 15 & 1995 & 2489.7 & 207.48 & 463.5 & 0.2 & 157.2111 & 24715.33 & 0.339182 \\
\hline 16 & 1996 & 2707.9 & 225.66 & 433.2 & 0.0 & 151.0093 & 22803.82 & 0.348590 \\
\hline 17 & 1997 & 1673.3 & 139.44 & 332.4 & 0.0 & 125.9893 & 15873.31 & 0.379029 \\
\hline 18 & 1998 & 2020.7 & 168.39 & 378.5 & 13.8 & 112.6689 & 12694.29 & 0.297672 \\
\hline 19 & 1999 & 2291.5 & 190.96 & 537.3 & 0.0 & 157.2851 & 24738.6 & 0.292732 \\
\hline 20 & 2000 & 2004.2 & 167.02 & 330.5 & 1.2 & 121.5739 & 14780.22 & 0.367849 \\
\hline 21 & 2001 & 2307.3 & 192.28 & 564.1 & 0.0 & 159.576 & 25464.50 & 0.282886 \\
\hline 22 & 2002 & 2315.7 & 192.98 & 424.3 & 0.0 & 148.5392 & 22063.89 & 0.350081 \\
\hline 23 & 2003 & 2298.3 & 191.53 & 433.0 & 4.5 & 130.6031 & 17057.18 & 0.301624 \\
\hline 24 & 2004 & 2367.8 & 197.32 & 559.8 & 1.5 & 176.8194 & 31265.11 & 0.315862 \\
\hline 25 & 2005 & 2621.2 & 218.43 & 567.3 & 2.0 & 160.1474 & 25647.18 & 0.282298 \\
\hline 26 & 2006 & 2475.8 & 206.32 & 427.4 & 0.0 & 151.9554 & 23090.45 & 0.355534 \\
\hline 27 & 2007 & 2670.7 & 222.56 & 436.1 & 0.0 & 154.1616 & 23765.80 & 0.353501 \\
\hline 28 & 2008 & 2210.7 & 184.23 & 485.1 & 0.0 & 156.6646 & 24543.81 & 0.322953 \\
\hline 29 & 2009 & 1911.4 & 159.28 & 381.8 & 0.0 & 118.6384 & 14075.07 & 0.310734 \\
\hline 30 & 2010 & 2412.0 & 201.00 & 472.1 & 0.0 & 160.775 & 25848.59 & 0.340553 \\
\hline 31 & 2011 & 3982.4 & 331.87 & 933.2 & 0.0 & 280.7446 & 78817.53 & 0.300841 \\
\hline 32 & 2012 & 4626.7 & 385.56 & 911.9 & 0.0 & 289.4497 & 83781.11 & 0.317414 \\
\hline 33 & 2013 & 4204.8 & 350.40 & 642.2 & 28.6 & 237.7294 & 56515.27 & 0.370180 \\
\hline
\end{tabular}




\section{REFERENCES}

[1] Akan, A. Osman (2006). Open Channel Hydraulics. First edition, Butterworth -Heinemann. http://books.elsevier.com.

[2] Akwa Ibom State Government (2008). Akwa Ibom State Wikipedia, the free encyclopedia. https://en.wikipedia.org/wiki/Akwa_Ibom_State.

[3] Al-Suhili, R. H. and Khanbilvardi, R. (2014). Frequency Analysis of the monthly Rainfall Data at Sulaimania Region, Iraq. American Journal of Engineering Research (AJER). Volume -03, Issue-05, pp 212 - 222. www.ajer.org. Open Access Journal, Retrieved on $10^{\text {th }}$ March, 2016.

[4] Arora, K. R. (2012). Irrigation, Water power and Water Resources Engineering. Standard Publishers Distributors, India.

[5] Chow, Ven Te, Maidment, David R. and Mays, Larry W. (1988). Applied Hydrology. McGraw-Hill Series in Water Resources and Environmental Engineering. International Edition 1988, pp 371 376

[6] Chow, V.T. (1951). A General Formula for Hydrologic Frequency Analysis. Transactions, American Geophysical Union, 32: $231-237$.

[7] Dike, B.U. and Nwachukwu, B.A. (2003). Analysis of Nigerian Hydrometeorological data. Nigeria Journal of Technology, Vol. 22, No. 1, March 2003.

[8] Ewemoje, T. A. and Ewemooje, O. S. (2011). Best distribution and plotting positions of daily maximum flood estimated at Ona River in Ogun - Oshun River Basin, Nigeria. Agricultural Engineering International: CIGR Journal, Vol. 13 No. 3, 2011. Manuscript No. 1380.

[9] Haan, C. T. (1994). Statistical Methods in Hydrology. Iowa State University Press. Ames.

[10] Izinyon, O. C. and Ajumuka, H. N. (2013). Probability Distribution Models for Flood Prediction in Upper Benue River Basin - Part II. Civil and Environmental Research, Vol. 3, No. 2, 2013, pp 62 - 74. International Institute for Science, Technology and Education (IISTE). http://www.iiste.org./Journals/ Online Journal
[11] Ke-Sheng Cheng, Jie-Lun Chiang and Chieh-Wei Hsu. (2006). Simulation of probability distributions commonly used in hydrological frequency analysis. Hydrological processes. Published online in Wiley InterScience (www.interscience.wiley.com). DOI: 10.1002/hyp.6176 Retrieved on $16^{\text {th }}$ March, 2016

[12] Khatsuria, R.M. (2005). Hydraulics of Spillways and Energy Dissipators. Marcel Dekker, 270 Madison Avenue, New York, NY 10016, USA. http://www.dekker.com.

[13] Kite, G. W. (1977). Frequency and Risk Analysis in Hydrology. Water Resources Publications. Fort Collins. Colorado.

[14] Mays, L. W. (2001). Water Resources Engineering. First Edition. John Wiley and Sons. Inc. pp $318-326$.

[15] Md. Mohsan Khudri and Farhana Sadia (2013). Determination of the Best Fit probability Distribution for Annual Extreme Precipitation in Bangladesh. European Journal of Scientific Research, Vol. 103, No. 3 June 2013, pp 391 - 404. Retrieved from http://www.researchgate.net/publication/242146889 on 10th March, 2016.

[16] Mustafa, S. and Yusuf, M. L. (1999). A Textbook of Hydrology and Water Resources. First Edition, Jenas Prints and Publishing Company, Abuja.

[17] Okonkwo, G. I. and Mbajiorgu, C. C. (2010). Rainfall Intensity Duration - Frequency Analysis for South Eastern Nigeria. Agricultural Engineering International: CIGR Journal 2010, 12 (1), pp $22-30$.

[18] Olafintoye, O. O., Sule, B.F. and Salami, A.W. (2009). Best - fit Probability distribution model for peak daily rainfall of selected cities in Nigeria. New York Science Journal, 2009, 2(3). http://www.sciencepub.net/newyork.

[19] Raghunath, H. M. (2006). Hydrology (Principles. Analysis. Design). Revised second edition. New Age International Publishers, New Delhi - 110002. www.newagepublishers.com.

[20] Subramanya, K. (2002). Engineering Hydrology. Second Edition. Tata McGraw-Hill publishing Company Limited, New Delhi, pp $241-254$ 